\title{
Expressions of Modality Associate Degree Business Explanation Essay Conclusions: A Functional Linguistic Perspective
}

\author{
Lok Ming Eric Cheung ${ }^{1}$ \\ ${ }^{1}$ Division of Languages and Communication, College of Professional and Continuing Education, The Hong \\ Kong Polytechnic University, Hong Kong Special Administrative Region, China \\ Correspondence: Lok Ming Eric Cheung, Division of Languages and Communication, College of Professional \\ and Continuing Education, The Hong Kong Polytechnic University, Hong Kong Special Administrative Region, \\ China.
}

Received: November 2, 2021

Accepted: December 17, $2021 \quad$ Online Published: December 23, 2021

doi: 10.5539/elt.v15n1p92

URL: https://doi.org/10.5539/elt.v15n1p92

\begin{abstract}
The rhetorically complex concluding components of academic written texts often challenge novice writers, having to summarise their arguments and stance, and offer prospective comments on future developments concerning the subject matter. With an aim to elucidate the lexicogrammatical expressions of such prospective comments in essay conclusions, the present study adopts the system of modality informed by Systemic Functional Linguistics (SFL) to examine the conclusions of explanatory essays written by non-native English speaking associate degree business students. The analysis compares the modality expressions deployed in highand low-graded essay conclusions, including modality types, explicitness, subjectivity and value. The analysis also investigates how the modality resources are combined for providing more than one comment in the conclusion. The findings show that high-graded texts have a more balanced choice of modality, less overly assertive features and more prospective comments, while they still require improvements on a more consistent deployment of modality features. This paper concludes with a brief discussion on teaching implications of the present study, in that writing instruction can make explicit the functions of different modality expressions and equip students with the linguistic repertoires appropriate for more formal and technical academic written registers.
\end{abstract}

Keywords: explanation essays, conclusion, modality, stance, Systemic Functional Linguistics (SFL)

\section{Introduction}

Academic writing is commonly associated with 'new ways of understanding, interpreting and organising knowledge' (Lea \& Street, 1998, p. 158). This means that the writing is expected to bring novel insights into current research, updating the field, and encouraging future research directions. Specifically, the conclusion of an academic text often offers a prospective focus (Hyland, 1990). Aside from a summarising the preceding content in the text, the conclusion typically includes future research recommendations, or a brief discussion that 'zooms out' of the specific context of the subject matter. Therefore, such concluding components are considered a crucial avenue for writers to both summarise and comment on the subject matter.

However, conclusions in academic texts are often rhetorically complex, and pose challenges to novice academic writers. Low et al.'s (2013) study highlighted the main issues in Asian novice writing, one of which involves the lack of justification and appropriateness in conclusions. Novice writers may conclude their texts without clearly stating the implications of their studies or over-generalise their findings, in that they make claims with a lack of justifiable grounds. Although research and teaching materials emphasise the importance of recapitulating the content and balancing evaluations when writing conclusions (Hamblin, 1981), novice writing often omit the latter criterion. The absence of the evaluative elements in conclusions can obscure writers' stances and insights.

While common strategies for closing an essay involve summarising main ideas with opinions, predictions, recommendations and hope (e.g. Cengage Learning, 2018; Oshima \& Hogue, 2007; Savage \& Mayer, 2006), the advice for writing effective essay conclusions has yet to include evaluative components in a more consistent manner. For example, Savage and Mayer (2006) provided valuable suggestions for expressing the writer's comments in conclusions of different essay types, but the general rhetorical focus only briefly mentions the need for 'summari[sing] the idea in the thesis statement' (Savage \& Mayer, 2006, p. 15) without evaluative 
components. Similarly, Oshima and Hogue (2007) mainly focused on the textual markers signalling the closing of the essay, but only briefly mentioned the kinds of comment writers can give. It was thus less clear as to how these concluding comments can be realised linguistically, and how they are adjusted in terms of certainty and obligation, particularly through choices of modality.

In light of this, the present study examines conclusions of explanation essays of English-as-a-second-language (ESL) associate degree students, in order to compare the high-graded and low-graded essays in terms of how modality are expressed and deployed strategically in the target textual focus. The analysis focuses on the modality expressions used with prospective comments, those that predict future trends and recommend desirable actions, as the writers close their essays. The findings are used to compare the frequencies of modality expressions, the ways they are realised in different lexicogrammatical and clausal structures, and the strengths and combinations of such expressions between the high- and low-graded texts. The theoretical and analytical framework adopted in the present study is that of Systemic Functional Linguistics (Halliday \& Matthiessen, 2014; Martin, 1995), which classifies the lexicogrammar for realising modality in a system of choices (See Section 3 for an elaboration of the modality system). This framework elucidates that different lexicogrammatical realisations of modality represent differences in the explicitness of the modal assessment (whether modality is expressed within a clause or outside as a projecting clause) and subjectivity (whether the assessor is present in the clause or not). Such different linguistic forms have significance, especially for writing instruction, in that writers may use various forms of modality for pragmatic purposes, such as avoiding and paraphrasing subjective assessments in academic writing.

Section 2 briefly reviews the literature on the structure of conclusions in academic written texts, and the prominent linguistic features for expressing stance in the conclusions. Section 3 elaborates and exemplifies the system network of modality, followed by a description of the research methods in Section 4. Section 5 lists the research questions, and Section 6 presents the findings comparing the conclusions of high- and low-graded essays. The present paper then discusses how the findings can inform teaching in Section 6, and concludes with future research directions.

\section{Literature Review}

\subsection{Structural Moves in the Concluding Components of Academic Written Texts}

The research on generic structuring of academic written discourses have centred around the three main schools of genre studies: the New Rhetoric Studies, English for Specific Purposes (ESP) and Systemic Functional Linguistics (Hyon, 1996). While studies of the overall genre staging of academic texts are present (e.g. Dreyfus et al., 2016; Lin \& Evans, 2012; Martin \& Rose, 2008; Rose \& Martin, 2012), many investigated the structural moves of individual sections, those of introductions (e.g. Hood, 2010; Swales \& Feak, 2004), methodology (e.g. Bruce, 2008; Cotos et al., 2017), discussions and conclusions (e.g. Bunton, 2005; Yang \& Allison, 2003). Regardless of their theoretical orientations, the investigations of academic written genres serve to make both the structural and linguistic features explicit, which inform both teaching and learning of writing for academic and specific purposes.

Being 'the point at which the writer stops explaining or defending the proposition to the end of the text' (Henry \& Roseberry, 1997, p. 483), the concluding components relate to the essay through offering insights into implications, knowledge, values and human experiences. As an obligatory component in academic writing (Hyland, 1990), conclusions comprise two main rhetorical moves, those of committing to the central idea and expanding the main idea to a wider context. The former move functions to end the essay and consolidate the author's arguments, whereas the latter move primarily serves to evaluate and predict. In the conclusion, the author may also suggest future directions for research or discussion, offering recommendations and stating opinions on the essay's main idea. This means that the commentaries made in essay conclusions contain both retrospective and prospective foci: while the former focus consolidates the ideas and stance established in the essay, the latter provides a view 'to unstated aspects of the discussion by widening the context' (Hyland, 1990, p. 74). Such a prospective focus is key to understanding the ways an essay can be taken beyond the specific context to the broader context of the issue for more general discussions and/or recommendations.

In the study of the conclusion chapters of PhD theses, Bunton (2005) discovered that the most common rhetorical structure involved that of a problem-solution. In such chapters, the writers recommend future research directions and describe practical implications or applications, aside from restating the research purposes and consolidating space for research. Studies on conclusions of research articles in different languages (Loi et al., 2016; Sheldon, 2018; Yang \& Allison, 2003) found similar structural moves, those which summarise and generalise the study and draw implications. These findings suggest that academic writers are required to possess 
both the subject knowledge and rhetorical knowledge in order to express opinions and commentaries for providing insights, improving research or solving relevant issues in their disciplines.

Despite the prolific research on conclusions, emphasis has been placed on investigating expert texts or persuasive essays (e.g. Lee, 2015; Thomas et al., 2015). Conclusions of essays produced by novice academic writers, such as students at the tertiary level, are seldom analysed. Admittedly, the rhetorical structures identified in these studies can inform academic literacy instruction, in that they shed light upon the general strategies for writing a conclusion across various text types. However, novice writers may find strategies identified in effective novice writing relevant to their education level and rhetorical needs, especially the strategies for expressing their original commentaries and in turn answering the 'so-what' question of writing about the chosen subject matter. These evaluative strategies in conclusions are pervasive across genres and serve important rhetorical functions in all essay types. For example, Martin and Rose (2008) identified evaluative language for closing different kinds of stories, such as evoking strong reactive responses in anecdotes, or telling a moral message at the end of narratives. Similar evaluative nature can be found in the conclusions of relatively more 'objective' explanatory essays, which illustrate factors contributing to a phenomenon, or outcomes arising from a phenomenon. Aside from reiterating the main ideas, the conclusion of an explanatory essay may also include the writer's opinion, predict future trends, offer recommendations, or a combination of these commentaries. Therefore, there is a need to investigate the concluding section of student essays, in order to reveal evaluative language features deployed specifically in the texts. In specific, the language for expressing and modifying the writers' stance is the focus of the present study, through which the writers adjust the degree of certainty and obligation in their statements. Relevant studies on stance in academic written discourses are briefly described in the following section.

\subsection{Linguistic Features for Expressing Stance in the Concluding Components in Academic Writing}

Given the interpersonal nature of academic writing, stance has been widely investigated in research studies on English for academic purposes (EAP) and writing pedagogies (e.g. Biber \& Conrad, 2019; Dreyfus et al., 2016; Hyland \& Guinda, 2012). The notion of stance is often discussed alongside linguistic concepts such as evidentiality (e.g. Chafe, 1986; Yang, 2014), engagement (e.g. Hyland, 2002, 2008), appraisal (e.g. Hood, 2010; Martin \& White, 2005/2007; White, 1998) and evaluation (Hunston, 2010, 2013). These notions refer to a similar interpersonal characteristic of stance-taking in academic written discourses: writers express their values, judgement and positioning in relation to their objects of study, other scholarly literature that they engage with, and their own research, upon which they shed a positive light. These stance-taking features often include modal verbs and modals ('may', 'must', 'seem to', 'need to'), adverbs ('possibly', 'perhaps', 'necessarily') and adjectives ('possible', 'imperative', 'necessary'). These lexicogrammatical features are typically used to denote two main kinds of stance: epistemic stance (adjusting certainty) and deontic stance (adjusting obligation and inclination).

The EAP research on stance in academic writing commonly investigates the expressions of stance across the whole academic text. Chen (2012) found that argumentative essays written by native English-speaking students were characterised by a wider range of epistemic modality expressions than the non-native English-speaking students. Additionally, the non-native speaking students' writing was found to be overly assertive, which are often unwarranted. This study corroborated studies on strong assertions and issues with qualifying statements in writing (e.g. Börjesson, 2014; Hyland, 1996; Hyland \& Milton, 1997). Hu and Li (2015) identified similar issues in novice writing by non-native English-speaking students as Chen (2012), including less-than-effective epistemic modality expressions, limited use of epistemic devices, and simpler syntactic constructions. They found that, however, more proficient non-native English-speaking students were more capable of using tentative markers and avoid being overly assertive. One of the possible reasons for the observed patterns of the use of epistemic devices, as $\mathrm{Hu}$ and $\mathrm{Li} \mathrm{(2015)}$ argued, was related to the way modality was instructed, such as the overuse of 'may' in ESL textbooks or style guides.

There were also studies investigating the language choice for expressing stance in the concluding components. Loi et al. (2016) identified the move of evaluating the study in research article conclusions written in English and Malay, suggesting the use of language expressing stance. They found that conclusions of English research articles (RAs) express a higher critical stance compared with their Malay counterparts. In specific, English RAs display a more assertive authorial positioning and attitude. The combination of language features articulating the authors' evaluative stance and dialogic (writer-reader) stance, adjusted by degrees of intensification or hedging, facilitates the impression of a compelling writer authority.

On the other hand, Hyland's (1990) study on the conclusion of the essay found that, the closing move providing a prospective view 'to unstated aspects of the discussion by widening the context' (Hyland, 1990, p. 74) is 
characterised by modals and conditionals ('if', 'unless'). Henry and Roseberry (1997) also identified similar linguistic features in essay conclusions, such as the use of future tense suggesting future outcomes, modals for adjusting the evaluations (e.g. 'can', 'may', 'seem') and verbs shedding positive light upon the future (e.g. 'solution', 'progress', 'extend'). These findings are similar to those examined in Sheldon's (2018) analysis more recently, illustrating how language features such as modality, concession, negation and projection contribute to 'opening up' the space for discussion in the research article conclusions. In specific, the use of modality 'construe[s] a heteroglossic backdrop... to create more space for refutation by or debate between writers and readers' (Sheldon, 2018, pp. 30-31). The above suggests that the identified language features play a crucial role for not just modifying the writer's stance, but also facilitating possibilities of discussion between the writer and the readership.

The choice of modality as outlined in the above studies, however, did not elucidate two main nuances resulting from different modality expressions. First, the kinds of stance (epistemic or deontic) realised through modality were not clearly differentiated. For example, while the orthographical forms of modal verbs are shared between the two stance types, the analysis of modality expressions necessitates whether they are deployed for adjusting certainty or obligation. Second, different expressions of modality have subtle differences, such as 'I think', 'may', 'perhaps' and 'it is possible', which represent a similar degree of certainty but differ in terms of whether the one making the modal assessment (i.e. the author) is foregrounded or backgrounded in the proposition. The subtle differences among various modality expressions as briefly explained above have to be examined systematically through a robust linguistic model that categorises the linguistic features of modality in terms of subjectivity (an overt display of the assessor) and explicitness (whether the assessment is made in the main clause or the projection clause), in addition to its types and intensity. Such an analysis serves to explain academic writing conventions such as avoiding the use of 'I think' from a linguistic perspective, in turn providing alternatives for making modal assessments that are relatively less personal or subjective. The next section elaborates on the system network of modality within the paradigm of Systemic Functional Linguistics (SFL), the theoretical and analytical framework for the analysis of the present study.

\section{Theoretical and Analytical Framework: Modality}

The present study adopted the system of modality informed by SFL (Halliday \& Matthiessen, 2014; Martin, 1995) for investigating the kinds of comments expressed in the students' essay conclusions. Based on the SFL illustration of the interpersonal functions of English language, ideas are exchanged and negotiated in the two main forms, those of 'propositions' and 'proposals'. Propositions are used for exchanging information through statements ('it is hot today.') and questions ('Is it hot today?'), whereas proposals are made for influencing behaviour, in the forms of offers ('let me take you to the beach.') and commands ('go to the beach with me!'). Importantly, these propositions and proposals are often arguable, meaning that alongside the extremes (it is (not) hot; do it/don't do it) there is a range of choices denoting the degree of certainty ('it will/must/may be hot.') and obligation ('you should/may/could do it'). These choices can be classified with the system of modality, part of which is illustrated in Figure 1 below:

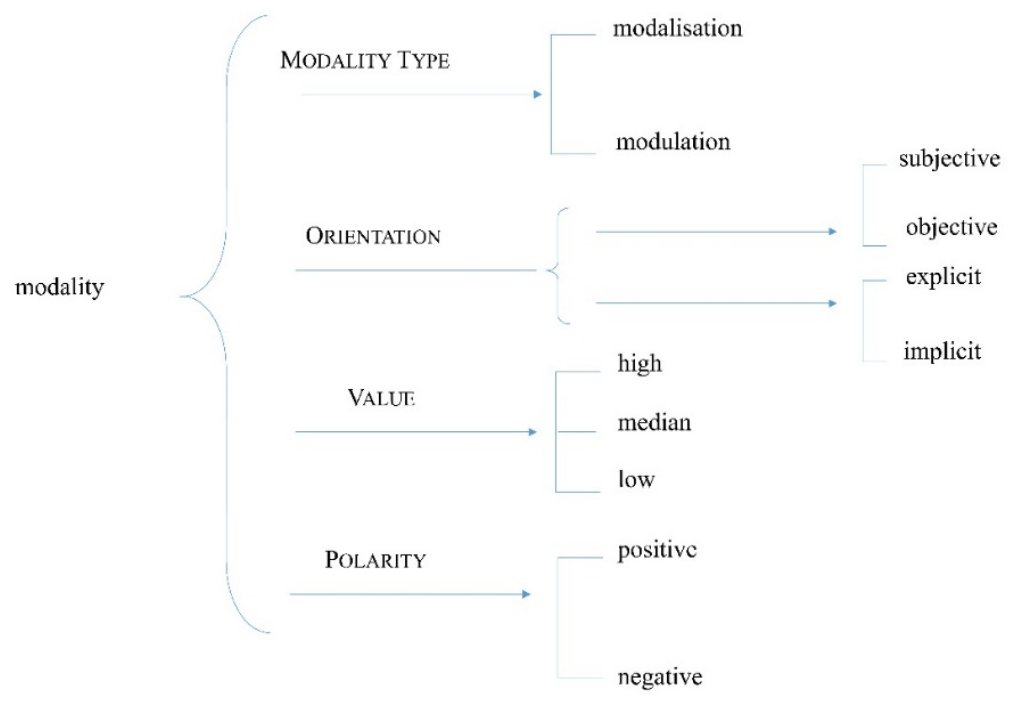

Figure 1. System network of modality (adapted from Halliday \& Matthiessen, 2014) 
The system of modality is divided into sub-systems of POLARITY, VALUE, TYPE and ORIENTATION (Note 1), the semantic choices of which are made synchronously. POLARITY represents the modality values expressed positively ('It may') or negatively ('It may not'), and VALUES can be adjusted across a scale from low ('can', 'could', 'might'), median ('may') to high ('should', 'must'). MODALITY TYPE is further categorised into modalisation and modulation. Modalisation refers to choices regarding the writer's assessment of probability (how likely?) or usuality (how frequently?) of a proposition; modulation refers to those regarding obligation (how obligatory?) and inclination (how preferably?) expressed in the proposition. The four modality types are exemplified below:

1) Probability: it is possible to attract passengers to stay and consume through the development of the tourism industry.

2) Usuality: Usually, the size of nano flats is within 12 square meters.

3) Obligation: As a member of Hong Kong, we should support the implementation of Lantau Tomorrow Vision.

4) Inclination: most of the youngster need to be free or do not want to follow traditional mindset.

The types of modality reflect two main kinds of comment, namely predication and recommendation respectively. Predictions are often expressed through the choice of probability, suggesting the likelihood of future events or trends to happen. Recommendations are made as the writer shifts the responsibility of the actions to be taken towards other actors through expressing obligation. In the present study, the annotation of the modality types aims to identify and differentiate the two types of comment, while the degree of which the writer articulates her/his presence in the text is examined through the choices of orientation (See Section 5.1 for the analysis of data).

ORIENTATION refers to the different clause structures and lexicogrammatical choices that are deployed for expressing subjectivity/objectivity and implicitness/explicitness of the modal assessment at stake. Subjectivity is expressed through the writer's presence in the text, often with the pronouns 'I' or 'we' collocating with verbs denoting mental judgements such as 'think', 'believe' and 'assert'. Additionally, the use of modal verbs implies the writer's assessment of the degree of certainty or obligation through modifying main verbs, and thus considered as 'subjective'. Objectivity refers to the choice of concealing the authorial presence from the clause or the use of adverbials or semi-modals in place of modal verbs, as the means of distancing the author away from the modal assessment. On the other hand, explicitness refers to how the modal assessment is expressed through the structure of the clause. Explicit expressions involve juxtaposing modal elements in the projecting clause (e.g. 'I think that...'; 'it is possible that...'), while implicit modality expressions are undertaken within the clause through modifying the main verb with modal verbs, semi-modals or adverbials.

The choices of ORIENTATION can form four combinations - explicit subjective, explicit objective, implicit subjective and implicit objective - that can be illustrated through a 2-by-2 matrix, with each cell exemplifying the generic lexicogrammatical choice. The following matrix in Table 1 exemplifies how modalisation is manifested in four different orientations:

Table 1. Examples of ORIENTATION - combinations of subjectivity and explicitness

\begin{tabular}{|c|c|c|c|}
\hline & \multicolumn{2}{|l|}{ Subjectivity } \\
\hline & & Subjective & Objective \\
\hline \multirow[t]{2}{*}{ Explicitness } & Explicit & $\begin{array}{l}\text { I believe/think/guess that...; I'm } \\
\text { sure/certain that... }\end{array}$ & $\begin{array}{l}\text { It is certain/probable/possible that...; } \\
\text { there is a possibility that... }\end{array}$ \\
\hline & Implicit & $\begin{array}{l}\text { Modal verbs (e.g. must, may, should, } \\
\text { can) and semi-modals (e.g. be likely to) }\end{array}$ & $\begin{array}{l}\text { Adverbials (e.g. certainly, probably, } \\
\text { possibly) }\end{array}$ \\
\hline \multicolumn{4}{|c|}{$\begin{array}{l}\text { The four combinations exemplified in Table } 1 \text { show that the same degree of possibility can be expressed in four } \\
\text { ways. The subtle differences lie in these four expressions are whether the authorial presence is foregrounded ('I I } \\
\text { think') or concealed/ implied ('Lantau Tomorrow Vision may') in terms of subjectivity, and whether the } \\
\text { modality is expressed within a simple clause or a projecting clause. The significance of differentiating these } \\
\text { modal orientations is to elucidate what it means by taking a stance 'objectively' in academic writing. While } \\
\text { explicit subjective expressions such as 'I think' may be favoured in personal academic texts such as reflections, } \\
\text { other manifestations may be preferred in more technical texts, those which foreground the phenomena within a } \\
\text { topic instead of expressing personal stance. }\end{array}$} \\
\hline
\end{tabular}




\section{Research Questions}

The present study raises the following research questions, which can be answered through the analysis of modality deployed in the concluding component of the students' essays. In particular:

1) What kind of prospective comments are common in the high- and low-graded texts?

2) In what ways the modal assessments are expressed in the high- and low-graded texts?

3) To what extent do the high- and low-graded texts adjust the degree of modality?

4) In what ways are the prospective comments combined in the high- and low-graded texts?

\section{Methodology}

The present study adopted both quantitative and qualitative approaches for analysing the collected data. The collected texts were annotated manually based on the modality framework informed by SFL (as elaborated in Section 2) in order to investigate the distribution of modality in the concluding paragraphs of the high- and low-graded student essays. The qualitative analysis involved a close examination of how student writers deployed multiple modality expressions in propositions and proposals as predictions and recommendations, as they summarised and closed their essays. The following outlines the procedures of data collection and analysis, and briefly discusses the issues regarding reliability and confidentiality.

\subsection{Data Collection and Analysis}

The data consists of 40 explanation essays (20 high-graded and 20 low-graded) written by non-native English business students from a community college in Hong Kong. These students attended a compulsory academic English course, requiring them to write a five-paragraph factorial (cause) or consequential (effect) explanation on a business topic, ranging from finance, human resources management, tourism and hospitality, as the end-of-semester term paper. The high-graded texts scored 77 marks in average (equivalent to a ' $\mathrm{B}+{ }^{\prime}$ ' or 'highly satisfactory' grade), while the average score of the low-graded texts is 43 marks (equivalent to a 'C-' or 'fair' grade). While all students were required to write within 400-450 words, the average length of the concluding paragraph of the concluding paragraphs in the high- and low-graded texts is 73 and 63 words respectively.

The conclusion of the essay is the main textual focus of the present study, where the student writers' comments bundled in the essays, as they were required to consolidate their evaluations using 'opinions', 'predictions' and 'recommendations', exemplified in Table 2. Opinions refer to the evaluation of the arguments within the scope of the essay, showing the writer's attitude typically through adjectives (Martin \& White, 2005/2007). Predictions and recommendations are regarded as 'prospective' comments: through predictions, the writer forecasts the future happenings in relation to the topic; through recommendations, s/he suggests potential actions for the responsible parties relevant to the topic to undertake as such.

Table 2. Comment types in the essay conclusions

\begin{tabular}{lll}
\hline Type & Explanation & Examples from the data \\
\hline Opinion & $\begin{array}{l}\text { Evaluating the positive or negative aspects } \\
\text { of the essay topic }\end{array}$ & $\begin{array}{l}\text { Besides, aside from the change of marketing } \\
\text { situation, the social atmosphere is the most } \\
\text { important factor to influence the market. }\end{array}$
\end{tabular}

Prediction

Forecasting future events potentially resulting from the phenomena discussed in the essay

Recommendation Identifying responsible institutions/persons who may undertake corresponding actions recommended by the writer
Not only will it furnish more job opportunities, sizeable pieces of land and attract tourists to Hong Kong...

Therefore, Hong Kong business market should increase its pace of investment in big data.

The two prospective comments, those of predictions and recommendations, were selected for the analysis to reveal how student writers express stances towards the topic knowledge through different strengths and orientations of modality (Yang et al., 2015). Predictions as propositions are adjusted through modalisation, which mainly represents various degrees of likelihood of a future event (e.g. 'Lantau Tomorrow Vision will...'). Recommendations as proposals are represented through modulation for negotiating obligation and inclination that the subject is responsible for taking future actions (e.g. 'The government should...'). The prospective comments allow writers to articulate their insights beyond the specific topic in the essay, and to 'zoom out' to evaluate the broader context surrounding the issue. 
The small dataset allowed for a detailed analysis of the concluding components. The unit of analysis in the present study is a clause, which is typically modalised or modulated for adjusting the prediction or recommendation therein. The essay conclusions were then annotated manually with UAM CorpusTool (O'Donnell, 2008), a multi-function corpus annotation and analysis software application, using the system of MODALITY (Halliday \& Matthiessen, 2014; refer to Section 2.1 for the system network) as the coding scheme. The annotated features were then counted to compare between the high-graded and low-graded texts in terms of the following, corresponding to the four research questions:

1) Types of modality (i.e. modalisation or modulation) for identifying the kinds of prospective comments;

2) Orientation and manifestation for identifying the explicitness and subjectivity of the modal assessment;

3) Value of the modal assessment (i.e. high, median or low); and

4) Combination of comments for finding out whether they are deployed individually or in combinations.

\subsection{Reliability of Data Annotation}

Given that the analysis involved manual annotation of language features, the following measures sought to ensure the reliability of the annotation. Firstly, the annotation was based on a robust linguistic framework, which corresponds the lexicogrammatical features with the semantic features representing modality, instead of coding according to the researcher's intuition or subjective categorisation of features. Secondly, the analysis and findings were checked by another teacher familiar with students' writing and interpersonal grammar from an SFL perspective. The analysis sought to reliably identify language features for constructing prospective comments as potentially useful resources for informing teaching and learning how to write essay conclusions with a persuasive 'punch' (Hood, 2010; Martin, 1995).

\subsection{Confidentiality}

The essay data was prepared observing the following procedures to ensure confidentiality. The students' consent was obtained so that the researcher was allowed to examine and publish findings based on the collected texts. Identity-revealing information, such as names and student numbers, was removed, alongside labelling each text with codes according to their grades (i.e. ' $\mathrm{H}$ ' and ' $\mathrm{L}$ ' stand for 'high' and 'low' respectively, such as 'H1', 'L1', etc.). Only excerpts of the essay texts were used for presenting findings as examples in the following sections.

\section{Findings and Discussion}

This section reports on the findings from the analysis of annotating features of modality, in order to compare the prospective commenting strategies between the high- and low-graded texts. The following illustrates the modality types, orientation and manifestation, value and combination of the comments in the essay conclusions. To supplement quantified results, the final part of this section presents one conclusion of a student's text that illustrates the deployment of prospective comments in the essay conclusion, which attempt to express the writer's insight into the topic.

\subsection{Types of Modal Assessment}

The analysis shows that a slightly higher number of modality is used in the high-graded texts than the low-graded ones (49 and 41 instances respectively), while the overall normalised results (per 1,000 words) do not show a very significant difference (33.56 and 32.54 respectively). However, in terms of modality types, high-graded texts deploy more modulation than the low-graded texts (8.90 and 6.35 instances per 1,000 words respectively), but less modalisation (24.66 and 26.19 per 1,000 words respectively). The figures are summarised in Table 3 below:

Table 3. Instances of modalisation and modulation in the high- and low-graded texts

\begin{tabular}{lllll}
\hline & \multicolumn{2}{l}{ High-graded texts } & \multicolumn{2}{l}{ Low-graded texts } \\
\cline { 2 - 5 } & $\begin{array}{l}\text { Frequencies } \\
\text { 1,000 words) }\end{array}$ & & Percentage (\%) & $\begin{array}{l}\text { Frequencies } \\
1,000 \text { words) }\end{array}$ \\
\hline Modalisation & $36(2.47)$ & 73.5 & $33(2.61)$ & 80.5 \\
Modulation & $13(0.89)$ & 26.5 & $8(0.63)$ & 19.5 \\
Total & $49(3.36)$ & 100 & $41(3.24)$ & 100 \\
\hline
\end{tabular}


This reflects that there is a more frequent use of recommendation, modified through modulation in the high-graded texts, while both high- and low-graded texts adjust prediction through similar number of modalisation features. In the predictive comments, the student writers' briefly forecast the potential development or trend of a phenomenon or an event stated in their essays, as exemplified in 1-4:

1) If the government does not take action now, the problem will become irreversible. (H2)

2) Also, not everyone can suffer the cost of health such organic food. (H9)

3) [A] part of Hong Kong people's lives could still be improved within their economic condition. (L10)

4) Lantau Tomorrow Vision may bring lots of drawbacks for Hong Kong's businesses... (L15)

The recommendations arise from the writers' judgements as to which institution or personnel is held accountable for taking actions, as exemplified in 5-8:

5) So many benefits the policy have [sic], Hong Kong should support this plan. (H15)

6) The government should put more effort on lower[ing] the number of nano flats. (H17)

7) The government should spend more resource on housing in order to tackle the problems. (L8)

8) [S]trict implementation shall be held in order to guarantee the quality of health food products... (L19)

The higher number of recommendations in high-graded texts suggest that the high-graded essay writers opted for shifting the modal responsibility (i.e. who is obliged to act according to the recommendation) towards the authority ('the government') or the general public ('Hong Kong'). This also suggests the writers' capability of 'zooming out' of the essay topic to offer insights into the broader scope of the topic.

\subsection{Orientation of the Modal Expressions}

The high-graded texts deployed a wider range of modality expressions in comparison to the low-graded texts, as illustrated in Table 4. Among the four types of ORIENTATION, both texts use a high number of implicit subjective expressions ( 2.60 and 2.46 per 1,000 words respectively). The high-graded texts used more instances of explicit subjective ( 0.14 and 0 per 1,000 words respectively), while using a similar number of implicit objective expressions ( 0.41 and 0.40 per 1,000 words respectively). The low-graded texts, however, utilised more explicit objective expressions ( 0.40 and 0.2 per 1,000 words respectively).

Table 4. Types of orientation in the high- and low-graded texts

\begin{tabular}{|c|c|c|c|c|}
\hline & \multicolumn{2}{|c|}{ High-graded texts } & \multicolumn{2}{|l|}{ Low-graded texts } \\
\hline & $\begin{array}{l}\text { Frequencies (per } \\
1,000 \text { words) }\end{array}$ & Percentage (\%) & $\begin{array}{l}\text { Frequencies (per } \\
1,000 \text { words) }\end{array}$ & Percentage $(\%)$ \\
\hline Explicit objective & $3(0.20)$ & 6.1 & $5(0.40)$ & 12.2 \\
\hline Explicit subjective & $2(0.14)$ & 4.1 & $0(0)$ & 0 \\
\hline Implicit objective & $6(0.41)$ & 12.2 & $5(0.40)$ & 12.2 \\
\hline Implicit subjective & $38(2.60)$ & 77.6 & $31(2.46)$ & 75.6 \\
\hline Total & $49(3.35)$ & 100 & $41(3.26)$ & 100 \\
\hline
\end{tabular}

The findings reflect that the typical choice for realising modality for both high- and low-graded texts is modal verbs (implicit subjective), compared with the use of adverbials (implicit objective; Example 9 and 10) and projecting clauses (explicit subjective and explicit objective, Example 11 and 12 respectively).

9) Without a doubt, big data is trendy and popular... (H6)

10) Indeed, nano flats will become a vitally important element of Hong Kong housing. (L8)

11) [W]e believed that big data will play a more indispensable role for many Hong Kong's company continuously. (H18)

12) [I]t is believed that the Lantau Tomorrow Vision can benefit Hong Kong people...

Aside from the straightforwardness, the preference for modal verbs over other lexicogrammatical expressions is possibly due to the students' observance of academic conventions, in that assertive adverbials such as 'certainly', 'surely', 'indeed' or subjective expressions such as 'I think', 'we believe' are generally avoided. However, two instances of explicit subjective orientation are present in the high-graded essays. This suggests that explicit expressions of authorial presence are not a determining factor for assessing whether a text is effectively written 
or not. This is especially true when emergent writers are developing writing repertoires matching with the academic conventions. Student writers are often confused when being asked to maintain objectivity while expressing opinions (Hood, 2004), in that they might consider explicit self-expressions as clear text signals for teachers to acknowledge their personal insights. While the use of personal references are not inappropriate and has organisational functions in academic written discourses, students may need to be informed of the patterns of personal pronoun use, such as collocating with verbs denoting research processes, e.g. the methodological 'I' (Harwood, 2005) and the genres embracing such use (e.g. personal reflections, narratives, etc.).

\subsection{Value of the Modal Assessment}

Both high- and low-graded texts express the writers' comments in a similar degree of intensity, with a predominant use of high and low values of modality. While both texts use median modality expressions the least ( $16.3 \%$ and $7.3 \%$ in high- and low-graded texts respectively), high-graded texts deploy more instances of median expressions than low-graded texts ( 0.55 and 0.24 per 1,000 words respectively). The distribution of the modality values in both set of texts is illustrated in Table 5 below.

Table 5. Frequencies of the modal assessment in high, median and low values

\begin{tabular}{llllll}
\hline & \multicolumn{2}{l}{ High-graded texts } & \multicolumn{2}{l}{ Low-graded texts } \\
\cline { 2 - 5 } & $\begin{array}{l}\text { Frequencies } \\
1,000 \text { words) }\end{array}$ & & Percentage (\%) & $\begin{array}{l}\text { Frequencies } \\
1,000 \text { words })\end{array}$ & \\
\hline High & $22(1.51)$ & 44.9 & $17(1.35)$ & 41.5 \\
Median & $8(0.55)$ & 16.3 & $3(0.24)$ & 7.3 \\
Low & $19(1.30)$ & 38.8 & $21(1.67)$ & 51.2 \\
Total & $49(3.36)$ & 100 & $41(3.26)$ & 100
\end{tabular}

While low modality in the students' texts is predominantly expressed through the modal verbs 'can' and 'could', modal assessment in high values encompasses grammatical classes, including modals 'must' and 'should', adverbials such as 'surely' and 'indeed', adjuncts such as 'without a doubt', in addition to cleft sentence structures as exemplified in Examples 13-16:

13) [P]eople need to keep it up and promote this lifestyle to friends. (L3)

14) [I]t is imperative for [the] government to have some measures to remedy the situation. (H2)

15) Obviously, the HK living culture was affected by the pressure of work. (L6)

16) There is no doubt that people are starting to support the new food industry of health food in recent years. (L17)

Median modal expressions also show similar variety. Aside from the modal verb 'may', common expressions include passive forms 'it is believed/recommended', or subjective 'we believed' and 'I perceive'. There are two instances of modality in the nominalised form that serves to summarise the specific suggestions and responsibility presented by the writer, as illustrated in Example 17 and 18:

17) They can encourage compan[ies] to offer more employee benefits... Also, [the] company can provide more freelance jobs... These suggestions can maintain... (H11)

18) The government surely has the responsibility to strengthen the surveillance of health food commercial events. (L17)

Based on the above findings, the students' choice of the intensity of modality in the comments suggests their assertiveness or cautiousness. This corroborates previous research studies on over-boosting and over-hedging in student writing (Aull \& Lancaster, 2014; McEnery \& Kifle, 2002), in that the students were yet to develop control of the modality resources and the intensity of the modality values. For example, some of the low values would incorporate personal attitude such as 'hopefully'; the high values such as 'without a doubt' and 'obviously' are overly assertive, and the median values, while scantly deployed, are often expressed with self-presence, such as 'in my view' and 'I perceive'. The over-assertiveness, alongside the explicit authorial presence, may result from the way students interpreted the essay requirement for giving 'opinions and attitudes', in that they mistook that it was necessary to explicitly signal their presence when giving 'personal opinions' (Unaldi, 2013). In light of this issue, teachers are recommended to explain more clearly about the rhetorical effects of various modality expressions aside from modal verbs, including their varying intensity. 


\subsection{Combination of Prospective Commenting Strategies}

The findings, summarised in Table 6 , show that the high-graded texts combine more prospective comments than low-graded texts in the conclusion paragraph. $90 \%$ of the high-graded texts would incorporate one or more comments in the conclusion, compared with only $80 \%$ of the low-graded texts would do so. On the other hand, there are more low-graded texts omitting prospective comments altogether (four instances compared with two instances in the high-graded texts).

Table 6. Number of prospective comments in each of the high- and low-graded texts

\begin{tabular}{lllll}
\hline & \multicolumn{2}{l}{ High-graded texts } & \multicolumn{2}{l}{ Low-graded texts } \\
\cline { 2 - 5 } & $\begin{array}{l}\text { Frequencies (per } \\
\text { 1,000 words) }\end{array}$ & Percentage (\%) & $\begin{array}{l}\text { Frequencies (per } \\
1,000 \text { words) }\end{array}$ & Percentage (\%) \\
\hline 5 comments or above & 3 & 15 & 2 & 10 \\
$\mathbf{2 - 4}$ comments & 10 & 50 & 10 & 50 \\
$\mathbf{1}$ comment & 5 & 25 & 4 & 20 \\
No comments & 2 & 10 & 4 & 20 \\
Total & 20 & 100 & 20 & 100 \\
\hline
\end{tabular}

Essays incorporating more prospective comments may perform better, given that student writers are more capable of 'zooming out' of the scope of the specific essay topic for discussing broader context of the issue through forecasting future trends, in addition to providing possible solutions and insightful recommendations for responsible parties (e.g. the government, the general public) to take actions.

However, the higher frequency of modality use does not guarantee an effective construal of the writer's stance. For example, expanding Example (17), as re-presented in (17a) below, it is found that the sentence before the two suggestions to the government uses a high value, compared with the two instances of 'can', suggesting a lower modality. Consequently, the hortatory tone may be rendered less consistent and stable.

17a) Government [sic] should do something to protect slash career. They can encourage compan[ies] to offer more employee benefits... Also, [the] company can provide more freelance jobs... These suggestions can maintain... (H11)

In another example from a low-graded text, as presented in (18), six instances of modality in various orientations and values are used:

18) It is true that the growth in health food market can provide job opportunities and promote a healthy lifestyle to the general public. Yet, the downsides mentioned above could lead to a great financial burden... the government surely has the responsibility to strengthen the surveillance of health food commercial events, strict implementation shall be held... (L19)

The first two instances of modality expressions are unproblematic, in that the writer concurred in her/his argument regarding the positive impact of 'the growth in health food market', which was countered in the second argument, signalled by the concessive marker 'yet'. However, the choice of modality from the second sentence onwards becomes less consistent, such as the weak modality 'could' following the discussed viewpoints in the essay body, which had been negatively valuated in the more definite term 'downsides', and the misuse of 'shall', which pragmatically refers to the high degree of commitment, in place of 'should' as a high degree of obligation. In addition, the argument that implicitly holds the government accountable, in the nominal form of modality 'the responsibility', also includes a highly assertive adverb 'surely'. The misuses of modal verbs and the over-assertiveness in the choice of modality reflect that the student writer may lack awareness of the pragmatic functions of modality in various forms and the less personal nature of academic registers. In addition, the above examples suggest that the frequent distribution of modality expressions may not correlate with the effectiveness of modality use in the text. The overuse of modality and the inconsistent modality choice bear the risk of contradicting the writer's arguments and undermining the overall persuasiveness of the text. Therefore, it is recommended that teachers illustrate clearly to students how modality is manifested in authentic texts by expert writers, aside from informing them of the individual lexicogrammatical items realising modality. It is equally important for students to understand about the meaning of such expressions in relation to their forms, especially when such shifts are often nuanced in varying subjectivity and explicitness (as explored in Section 5.2 regarding orientation). 


\section{Teaching Implications}

The above analysis has explicated how student writers focus on particular lexicogrammatical forms for expressing modality, and provided insights into how the different forms achieve varying degrees of 'author visibility', through which 'authors put forward their own explicit interpretations of the subject matter' (Myskow, 2018 , p. 54). The above findings and discussion, however, are not to suggest that student writers cannot use personal pronouns in any academic writing as a rule. In fact, authorial presence (the use of 'I' or 'we') has certain textual functions, such as recounting research procedures, the 'Methodological I' as proposed by Harwood (2005). Instead, explicit expressions of viewpoints are more likely to appear in spoken registers or personal reflections, and can be replaced by the implicit alternatives so that the discussions on the topic are foregrounded. In other words, the alternative modality expressions can preferably be regarded as methods for 'paraphrasing' personal, subjective expressions for fulfilling the register expectations on academic essays at the tertiary level.

Therefore, in order to help student appropriate different manifestations of modality in essay conclusions, there is a need for teachers to clarify how students are expected to express their opinions in two main aspects. First, teachers need to explain clearly how students are required to write in response to essay prompts that directly address them (e.g. 'Do you agree that...', 'what do you think...'). Differing from writing at the secondary level, the teachers of which may favour an intimate, sincere tone (Jeffery, 2011), writing at the advanced level may require more control, resembling a less personal yet more professional, distant tone. This means that students are not expected to answer the essay prompts directly with overt authorial presence ('I agree...', 'I think...'). Second, teachers also need to clearly explain what language choices to make when students take a stance towards the subject matter, using a tone appropriate to the discipline's requirements. Students may feel less secure about not using subjective expressions for personal opinions, or confused as to what it means by making 'objective critique' (Hood, 2004, 2010) in critical discussions on the subject matter. As illustrated through the functional linguistic perspective, the present study has demonstrated that modal assessments can be manifested in different lexicogrammatical forms, meaning that opinions expressed without authorial presence still represent the author's views. In explanation essays, the main favoured language choice involves those providing 'domain-specific, factual, precise description' (Jeffery, 2011, p. 101). Therefore, choices of modality and its strengths would be dependent upon how writer are certain or assertive about their arguments. It is, however, necessary for teachers to explain in what ways students can manage their modal assessments, such as down-toning when statements are personal claims instead of facts, and ensuring that the modal assessments are made consistently across the text.

\section{Conclusion}

The present study has identified linguistic features deployed for expressing modality and adjusting the prospective comments on the subject matters in the high- and low-graded essay conclusions. The quantitative approach has characterised the differences between the high- and low-graded texts in modality type, orientation, values and combinations. The present study has found that the high-graded texts have a more balanced choice of modalisation (for predictions) and modulation (for recommendations). Fewer explicit objective expressions are used, especially the highly assertive adverbial markers (i.e. 'certainly', 'definitely'). In terms of bundling comments in the conclusion, high-graded texts utilise more prospective comments that offer insights into the future trends and predictions, in addition to potential solutions relevant to the essay topics.

That said, as novice writing, the high-graded essay conclusions share similar issues with the low-graded texts in relation to register awareness, and thus pragmatic use of modality. Explicit subjective orientations (e.g. 'I think', 'we believed') are present in high-graded texts, and the modality values selected are predominantly of high and low values, suggesting that the writers are overly assertive or excessively cautious when giving suggestions or recommendations. On the other hand, the qualitative analysis has found that, despite a higher frequency of modality use, how the expressions of modality are organised in the high-graded texts may lack consistency, in potentially contradicting within the conclusion. The above findings suggest that student writers, with the knowledge of modality in terms of form, lack an understanding about how each of the different forms function in academic writing, and have 'difficulty conveying the appropriate degrees of qualification and confidence' (Hyland \& Milton, 1997, p. 322). The present study has explained more clearly how commentaries in essay conclusions are realised from a linguistic perspective, and revealed that the cautiousness and consistency of modality choices plays a more significant role than the distribution and frequencies of such choices in establishing and maintaining the writer's stance. 
Given the textual focus on essay conclusions, the limitations of the present study will be resolved by future studies. First, aside from concluding paragraphs, concluding sentences in body paragraphs are also the main sites for writers to summarise and commenting on the subject matter. Future research will examine and compare the differences in evaluative and stance-taking strategies between these two textual positions. Second, the present study did not include the investigation of linguistic strategies for opinions, as the linguistic focus is that of modality expressions. Opinions may be marked by overt authorial presence (e.g. 'in my opinion', 'from my perspective'), and characterised by attitudinal lexis such as adjectives (e.g. important, prominent), nouns (e.g. significance, problems) and adverbs (e.g. clearly, skillfully). It is worthwhile examining the distribution and types of such features in high- and low-graded essays, either through corpus approaches or text analytic approaches with the framework of Appraisal (Martin \& White, 2005). Despite the limitations, the main contribution of the present study aims to inform academic writing instruction, raising students' awareness about the need for including comments with the modality expressions appropriate to the academic conventions, in order to add evaluative 'punches' to the essay conclusion.

\section{Acknowledgements}

The work described in this paper, was substantially supported by a grant from the College of Professional and Continuing Education, an affiliate of The Hong Kong Polytechnic University.

\section{References}

Aull, L. L., \& Lancaster, Z. (2014). Linguistic markers of stance in early and advanced academic writing: A corpus-based comparison. Written Communication, 31(2), 151-183. https://doi.org/10.1177/0741088314527055

Biber, D., \& Conrad, S. (2019). Register, Genre, and Style. Cambridge: Cambridge University Press. https://doi.org/10.1017/9781108686136

Börjesson, V. (2014). "Completely Headless". Modification of adjectives in Swedish advanced learners' English [Doctoral thesis, University of Gothenburg]. Sweden. Retrieved from https://hdl.handle.net/2077/35604

Bruce, I. (2008). Cognitive genre structures in Methods sections of research articles: A corpus study. Journal of English for Academic Purposes, 7(1), 38-54. https://doi.org/10.1016/j.jeap.2007.12.001

Bunton, D. (2005). The structure of PhD conclusion chapters. Journal of English for Academic Purposes, 4(3), 207-224. https://doi.org/10.1016/j.jeap.2005.03.004

Cengage Learning. (2018). College English. National Geographic Learning.

Chafe, W. (1986). Evidentiality in English conversation and academic writing. In W. Chafe \& J. Nichols (Eds.), Evidentiality: The linguistic coding of epistemology (pp. 261-272). Ablex.

Chen, Z. (2012). Expression of Epistemic Stance in EFL Chinese University Students' Writing. English Language Teaching, 5(10). https://doi.org/10.5539/elt.v5n10p173

Cotos, E., Huffman, S., \& Link, S. (2017). A move/step model for methods sections: Demonstrating rigour and credibility. English for Specific Purposes, 46, 90-106. https://doi.org/10.1016/j.esp.2017.01.001

Dreyfus, S. J., Humphrey, S., Mahboob, A., \& Martin, J. R. (2016). Genre pedagogy in higher education: The SLATE project. Palgrave Macmillan. https://doi.org/10.1007/978-1-137-31000-2

Halliday, M. A. K., \& Matthiessen, C. M. (2014). Halliday's introduction to functional grammar (4th ed.). Routledge. https://doi.org/10.4324/9780203783771

Hamblin, D. (1981). Teaching study skills. Wiley-Blackwell.

Harwood, N. (2005). A corpus based study of self-promotional I and we inacademic writing across four disciplines. Journal of pragmatics, 37, 1207-1231. https://doi.org/10.1016/j.pragma.2005.01.012

Henry, A., \& Roseberry, R. L. (1997). An investigation of the functions, strategies and linguistic features of the $\begin{array}{lllll}\text { introductions and } & \text { conclusions of essays. System, 25(4), }\end{array}$ https://doi.org/10.1016/S0346-251X(97)00047-X

Hood, S. (2010). Appraising research: Evaluation in academic writing. Palgrave Macmillan. https://doi.org/10.1057/9780230274662

Hu, C., \& Li, X. (2015). Epistemic Modality in the Argumentative Essays of Chinese EFL Learners. English Language Teaching, 8(6). https://doi.org/10.5539/elt.v8n6p20 
Hunston, S. (2010). Corpus approaches to evaluation: Phraseology and evaluative language. Routledge. https://doi.org/10.4324/9780203841686

Hunston, S. (2013). Systemic functional linguistics, corpus linguistics, and the ideology of science. Text \& Talk, 33(4-5), 617-640. https://doi.org/10.1515/text-2013-0028

Hyland, K. (1990). A genre description of the argumentative essay. RELC journal, 21(1), 66-78. https://doi.org/10.1177/003368829002100105

Hyland, K. (1996). Nurturing hedges in the ESP curriculum. System, 24(4), 477-490. https://doi.org/10.1016/S0346-251X(96)00043-7

Hyland, K. (2002). Directives: Argument and engagement in academic writing. Applied linguistics, 23(2), 215-239. https://doi.org/10.1093/applin/23.2.215

Hyland, K. (2008). Disciplinary voices: Interactions in research writing. English Text Construction, 1(1), 5-22. https://doi.org/10.1075/etc.1.1.03hyl

Hyland, K., \& Guinda, C. S. (2012). Stance and voice in written academic genres. Palgrave Macmillan. https://doi.org/10.1057/9781137030825

Hyland, K., \& Milton, J. (1997). Qualification and certainty in L1 and L2 students' writing. Journal of Second Language Writing, 6(2), 183-205. https://doi.org/10.1016/S1060-3743(97)90033-3

Hyon, S. (1996). Genre in three traditions: Implications for ESL. Tesol Quarterly, 30(4), 693-722. https://doi.org/10.2307/3587930

Jeffery, J. V. (2011). Subjectivity, intentionality, and manufactured moves: Teachers' perceptions of voice in the evaluation of secondary students' writing. Research in the Teaching of English, 92-127. Retrieved from https://www.jstor.org/stable/23050590

Lea, M. R., \& Street, B. V. (1998). Student writing in higher education: An academic literacies approach. Studies in Higher Education, 23(2), 157-172. https://doi.org/10.1080/03075079812331380364

Lee, S. H. (2015). Evaluative stances in persuasive essays by undergraduate students: Focusing on APPRECIATION resources. Text \& Talk, 35(1), 49-76. https://doi.org/10.1515/text-2014-0029

Lin, L., \& Evans, S. (2012). Structural patterns in empirical research articles: A cross-disciplinary study. English for Specific Purposes, 31(3), 150-160. https://doi.org/10.1016/j.esp.2011.10.002

Loi, C. K., Lim, J. M. H., \& Wharton, S. (2016). Expressing an evaluative stance in English and Malay research article conclusions: International publications versus local publications. Journal of English for Academic Purposes, 21, 1-16. https://doi.org/10.1016/j.jeap.2015.08.004

Low, H. M., San, P. H., Petras, Y., \& Mohamad, A. R. (2013). Novice Writers in Asian academia: Insights on writing issues. 3L: Language, Linguistics, Literature, 19(3), 47-60. Retrieved from https://ejournal.ukm.my/31/issue/archive

Martin, J. R. (1995). Interpersonal meaning, persuasion and public discourse: Packing semiotic punch. Australian Journal of Linguistics, 15(1), 33-67. https://doi.org/10.1080/07268609508599515

Martin, J. R., \& Rose, D. (2008). Genre relations: Mapping culture. Equinox.

Martin, J. R., \& White, P. (2005). The evaluation of language: Appraisal in English. Palgrave Macmillan.

McEnery, T., \& Kifle, N. A. (2002). Epistemic modality in argumentative essays of second-language writers. In J. Flowerdew (Ed.), Academic discourse (pp. 182-195). Routledge.

Myskow, G. (2018). Changes in attitude: Evaluative language in secondary school and university history textbooks. Linguistics and Education, 43, 53-63. https://doi.org/10.1016/j.linged.2017.12.001

O'Donnell, M. (2008). The UAM CorpusTool: Software for corpus annotation and exploration.

Oshima, A., \& Hogue, A. (2007). Introduction to academic writing (3rd ed.). Pearson/Longman.

Rose, D., \& Martin, J. R. (2012). Learning to write, reading to learn: Genre, knowledge and pedagogy in the Sydney School. Equinox.

Savage, A., \& Mayer, P. (2006). Effective academic writing: the short essay. Oxford University Press. 
Sheldon, E. (2018). Dialogic spaces of knowledge construction in research article Conclusion sections written by English L1, English L2 and Spanish L1 writers. Ibérica: Revista de la Asociación Europea de Lenguas para Fines Especificos (AELFE), (35), 13-40.

Swales, J. M., \& Feak, C. B. (2004). Academic writing for graduate students: Essential tasks and skills (Vol. 1). University of Michigan Press.

Thomas, D. P., Thomas, A. A., \& Moltow, D. T. (2015). Evaluative stance in high achieving Year 3 persuasive texts. Linguistics and Education, 30, 26-41. https://doi.org/10.1016/j.linged.2015.03.003

Unaldi, I. (2013). Overuse of discourse markers in Turkish English as a foreign language (EFL) learners' writings: The case of 'I think' and 'in my opinion'. The Anthropologist, 16(3), 575-584. https://doi.org/10.1080/09720073.2013.11891383

Yang, L. (2014). Evidentiality in English Research Articles of Applied Linguistics: From the Perspective of Metadiscourse. Journal of Language Teaching \& Research, 5(3). https://doi.org/10.4304/j1tr.5.3.581-591

Yang, R., \& Allison, D. (2003). Research articles in applied linguistics: Moving from results to conclusions. English for Specific Purposes, 22(4), 365-385. https://doi.org/10.1016/S0889-4906(02)00026-1

\section{Note}

Note 1. Under the SFL convention, system labels are printed in small capitals.

\section{Copyrights}

Copyright for this article is retained by the author(s), with first publication rights granted to the journal.

This is an open-access article distributed under the terms and conditions of the Creative Commons Attribution license (http://creativecommons.org/licenses/by/4.0/). 